Discussion Paper No. 06-002

\title{
Heterogeneous Returns to Training An Analysis with German Data Using Local Instrumental Variables
}

Anja Kuckulenz and Michael Maier

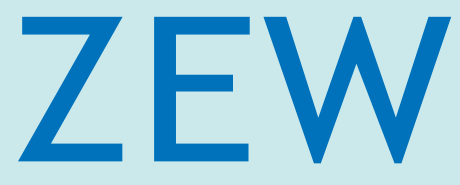

Zentrum für Europäische Wirtschaftsforschung $\mathrm{GmbH}$

Centre for European

Economic Research 
Discussion Paper No. 06-002

\section{Heterogeneous Returns to Training An Analysis with German Data Using Local Instrumental Variables}

Anja Kuckulenz and Michael Maier

Download this ZEW Discussion Paper from our ftp server:

ftp://ftp.zew.de/pub/zew-docs/dp/dp06002.pdf

Die Discussion Papers dienen einer möglichst schnellen Verbreitung von neueren Forschungsarbeiten des ZEW. Die Beiträge liegen in alleiniger Verantwortung der Autoren und stellen nicht notwendigerweise die Meinung des ZEW dar.

Discussion Papers are intended to make results of ZEW research promptly available to other economists in order to encourage discussion and suggestions for revisions. The authors are solely responsible for the contents which do not necessarily represent the opinion of the ZEW. 
Non-technical summary

Investment in continuing vocational training constitutes a major part of post school human capital increment. Obviously, heterogeneity of employees plays a role not only in obtaining skills, but also in economic consequences of education and training.

Empirical work on the wage impact of training has noted that unobserved heterogeneity of training participants should play a role. The expected return to training, which partly depends on unobservable characteristics, is likely to be a crucial criterion in the decision to take part in training or not. Therefore, the decision to take part in continuous training is likely to be influenced by the expected returns to training; i.e. those workers for whom the expected return is higher will obtain more training than other workers for whom the expected return is lower. Hence, participants and nonparticipants in training are unlikely to have the same observed and hypothetical returns. Severe econometric problems are therefore posed by the endogeneity of training decisions.

While former empirical work with German data has extensively analyzed the wage effect of training, none of them has accounted for the likely possibility that worker selection into training is based on the expected heterogeneous return to continuous training. We try to account for this by using recent advances in estimating returns to schooling, which allow for selection on unobservables, and apply it to estimating the impact of training on earnings. Allowing heterogeneity to be unobserved by the econometrician, but assuming that individuals may act upon this heterogeneity, completely changes the interpretation and properties of commonly used estimators.

We use German survey data from 1998/1999 and the Local IV method, which allows for observed as well as unobserved heterogeneity and that selection into training may depend on both. Our LIV estimate is much lower than the relevant OLS and IV estimate (and furthermore, insignificant). We cannot find any causal effect of training on wages when taking into account that more able and motivated individuals participate in training, or those which are on a promotion path where training courses are part of the way. 


\title{
Heterogeneous Returns to Training. An Analysis with German Data Using Local Instrumental Variables $^{1}$
}

\author{
Anja Kuckulenz and Michael Maier \\ ZEW Mannheim
}

January 10, 2006

\footnotetext{
${ }^{1}$ We thank Alexandra Spitz, Thomas Zwick, and seminar participants in Mannheim for helpful comments. We also thank Iliyan Stankov for his research assistance. This work was supported by the Deutsche Forschungsgemeinschaft (DFG) through the research group Heterogeneous labor. Neither the Bundesinstitut für berufliche Bildung (BIBB), the Institut für Arbeitsmarkt- und Berufsbildung (IAB) nor the Zentralarchiv (ZA) take any responsibility for the analysis or the interpretation of the data presented here.
} 


\begin{abstract}
Empirical work on the wage impact of training has noted that unobserved heterogeneity of training participants should play a role. The expected return to training, which partly depends on unobservable characteristics, is likely to be a crucial criterion in the decision to take part in training or not. We try to account for this fact by using recent advances in estimating returns to schooling, which allow for selection on unobservables, and apply it to estimating the impact of training on earnings. Allowing heterogeneity to be unobserved by the econometrician, but assuming that individuals may act upon this heterogeneity, completely changes the interpretation and properties of commonly used estimators. Our results based on local instrumental variables suggest that traditional estimates of the wage impact of training overestimate this effect.
\end{abstract}

Keywords: Vocational training, treatment effects, semiparametric estimation, Local instrumental variables

JEL-Codes: J31, C14, C21 


\section{Introduction}

Investment in continuing vocational training constitutes a major part of post school human capital increment. A survey conducted by the IW Cologne (Institut der deutschen Wirtschaft Köln) in cooperation with the chambers of commerce and crafts shows that German companies consider training important to enhance their competitiveness. In 2001, firms invested nearly 17 billion Euro in continuing vocational training (Weiß, 2003). Almost all companies offer training and about half of the employees participated in seminars, courses or on-the job training. Since 1998, when the last IWsurvey on continuing vocational training was conducted, companies have cut the duration of training spells and expenditure per employee to improve the efficiency of training. Since the total number of training participants increased at the same time, total investment in continuing vocational training remained at the same spending level as in 1998 (Weiß, 2000).

Participation depends on workplace and employee characteristics. In Germany, around 80 percent of high qualified workers take part in training at least once in 1997-1999, but less than 30 percent of those workers which are less qualified participate (Kuckulenz and Zwick, 2003). Employees in small firms participate less in training than those in large firms and also women, foreigners, and workers above forty years of age receive less training (Pischke, 2001).

Obviously, heterogeneity of employees plays a role not only in obtaining skills, but also in economic consequences of education and training. As noted by the OECD (2004), only little is known about how the training impact on wages varies across heterogeneous training participants. The small empirical literature with German data has shown that training type as well as worker, job, and firm characteristics determine the wage impact of training. Recently, Pannenberg (1998), Jürges and Schneider (2005) and Kuckulenz and Zwick (2003) have compared the wage effects of subgroups of employees with German data. Other work concentrates on certain aspects of heterogeneity, e.g. differences in training returns between employees with different educational backgrounds (Lynch, 1992; Blundell, Dearden and Meghir, 1996; OECD, 1999; OECD, 2004), age (OECD, 2004), men and women (Pischke, 2001) or tenure (Pannenberg, 1998). Some of these papers come up with rather high estimates for the impact of training on wages which could be explained by unobserved factors: e.g. whether an employee is on a promotion path, climbing a steep ladder upwards or how able and motivated someone is. Pfeiffer and Reize (2001) interpret their results to show that training and career paths are intertwined and that higher wages may not actually be the consequence of training, but result from excellent career management. Likewise, Pischke (2001) finds that selection in training seems not to be based on wage levels but rather on earnings growth. For an overview of recent international estimates of wage returns to continuing vocational training, 
compare Leuven (2005).

Recent literature on the returns to schooling provides methods which allow that returns may vary across schooling types and participants. Carneiro, Heckman and Vytlacil (2003) apply methods which allow for the likely fact that the expected return of the investment in human capital plays a role when deciding about the investment. Among others, also Blundell, Dearden and Sianesi (2005) have noted the importance of allowing for (observable) heterogeneity in returns to education. Selection into training may depend much more on individuals' ability and motivation than does selection into schooling, where family background characteristics are the main determinants (Ammermüller, 2004; Lauer, 2002). Also, training costs and maybe even training returns are more obvious and hence may play a more crucial role for the decision to take part in training than for the schooling decision. Our study uses recent econometric methods, which allow for selection on unobservables, and apply it to estimating the impact of training on earnings. With German survey data from 1998/1999, we explore the heterogeneity of training returns and how this may affect participation in training. By using the Local Instrumental Variables (LIV) method, we account for the heterogeneity of training returns in our analysis and allow for observed as well as unobserved heterogeneity. Therefore, the assumptions are much less stringent than those of ordinary least squares or conventional IV regressions. In fact, if unobserved heterogeneity is relevant and individuals act upon it, OLS and linear IV estimates can be seriously misleading (see Heckman and Vytlacil, 2005).

The following section provides a brief discussion of the theoretical background and previous empirical work. In the following, first the econometric method used is introduced, second the data set is described, and third the implementation and the estimation results are presented. The last section concludes and gives an outlook.

\section{Background Discussion}

It has been noted in the literature that bargaining and rent-sharing between employer and employee should have an impact on the share of the rent generated by training which is granted to the training participant (e.g. Dearden, Reed and Van Reenen, 2000 and Arulampalam, Booth and Bryan, 2004). Therefore, heterogeneity in training returns cannot only be explained by differences in productivity effects of training, but also by differences in individual, firm, and job characteristics which relate to the bargaining power of employer and employee. Lazear (1979) notes that wages and productivity at a given point in the career do not have to correspond. Employees may first receive wages that are lower than their productivity and at a later stage of their professional career, they can profit from early investments in their 
human capital. In contrast, training demand should be highest for firm entrants and also the productivity effect of training should then be highest for this group. The return to training for workers with low qualifications should be higher if individuals with low qualifications are constrained in their choice of education. On the other hand, it may be that employer provided training is complementary to education (Blundell, Dearden and Meghir, 1999) and therefore favors higher skilled employees.

Kuckulenz and Zwick (2003) find with German data that the effect of training on earnings differs between agents with a broad spectrum of different characteristics and between firms with different characteristics. High-skilled employees profit more from training than low-skilled workers, the training earnings mark-up increases with professional experience but decreases with company tenure. Employees with previous unemployment spells and employees with temporary contracts profit less from training. Smaller firms, firms in a good economic situation, and firms that share profits with their employees pay a higher training earnings mark-up. The authors interpret these findings as evidence that the training wage effect not only depends on the productivity increase induced by training, but also on the bargaining position between employer and employee. Hence, the increase in productivity caused by training must not directly correspond to the wage effect of training. Nevertheless, the wage impact of training is frequently taken as (the lower bound of) the productivity impact of training (Blundell, Dearden and Meghir, 1999).

The decision to take part in continuous training is likely to be influenced by the expected returns to training; i.e. those workers for whom the expected return is higher will obtain more training than other workers for whom the expected return is lower. Hence, participants and nonparticipants in training are unlikely to have the same observed and hypothetical returns. Severe econometric problems are therefore posed by the endogeneity of training decisions. While former empirical work with German data has extensively analyzed the wage effect of training, none of them has accounted for the likely possibility that worker selection into training is based on the expected heterogeneous return to continuous training.

Previous work has solved the endogeneity problem by using a Heckmantype selection correction term from a training participation equation (e.g. Lynch, 1992). Also Blundell, Dearden and Meghir (1996) argue that continuous training might be correlated with transitory shocks to productivity and therefore include a Heckman correction term into their wage growth equation. Other authors tried to tackle the endogeneity problem by using instrumental variable estimation (Leuven and Oosterbeek, 2001 or Kuckulenz and Zwick, 2003) or nonparametric matching methods (Gerfin, 2004). Also, fixed effects estimators have been used (Booth and Bryan, 2005; Pischke, 2001 or Barron, Berger and Black, 1999), which produce unbiased estimates whenever unobserved individual effects are permanent. Leuven and Ooster- 
beek (2002) use a different approach to estimate the causal effect of training on wages by using information about workers who planned to participate in training but did not due to some exogenous event. They use this group of workers as the comparison group and assume that within their sample, participation in training is random.

The estimated least-squares coefficient of the individual's choice parameter is only then to be interpreted as the causal effect of training on wages if workers are randomly assigned to take part in training. We have argued above that employees are either chosen by the employer providing training or that they select themselves into training and this implies that standard estimations using least squares produce biased results. Therefore, we rely on recent advances in estimating the returns to schooling using evaluation methods. In the literature, which was mainly spurred by Heckman and coauthors, schooling is treated as an endogenous variable in the standard wage function.

While former work on training in Germany relied on the unconfoundedness or selection on observables assumption, we want to explicitly allow for heterogeneity of wage effects of training and for selection on unoberservables. With detailed information about the qualification profile and professional history of workers, the organizational and technological condition of workplaces, as well as some employer characteristics, we are able to explain a large part of the variation in wages. Nevertheless, some characteristics which are crucial for the selection into training are missing; above all ability, motivation and the information whether individuals are on a promotion path. Former work has also shown that workers with higher wage growth participate more often in training (Pischke, 2001). With our cross section data, we cannot account for this directly since we observe wages only once.

The advantage of the econometric model we are using is that it allows the effect of training to vary both in terms of observed and unobserved factors. Firms may offer training to those workers who are expected to be more productive after training or those workers who expect wage gains from training participation may select themselves into training courses. Since the probability of treatment increases with the gains from treatment, we allow the impact of training on earnings to differ across individuals and for selection on gains. Hence, we assume that individuals are forward looking agents who have expectations on the impact of training participation on their wage. Adequate instrumental variables have to be found that explain the selection into training participation in order to correct for treatment selection. We should stress again that under the heterogeneity assumptions stated above, conventional IV methods will not yield unbiased results. To get reliable results, much stronger assumptions on effect heterogeneity or individual choice behavior have to be imposed, which might be implausible in our case. Therefore, if no stronger assumptions can be made, evaluation methods like the local IV model are necessary to estimate the impact of 
training on earnings.

\section{Econometric Model}

The causal effects of training on earnings are analyzed within the framework of econometric evaluation methods. These methods take into account heterogeneous effects of training for each individual, which may depend on observable or unobservable factors. Allowing heterogeneity to be unobserved by the econometrician, but assuming that individuals act upon this unobserved heterogeneity completely changes the interpretation and properties of common estimators taking (observed) heterogeneity into account. Carneiro, Heckman and Vytlacil (2003) and Heckman and Vytlacil (2005) show that conventional IV estimators substantially misestimate the average marginal return and policy relevant effects.

Two main streams of non-experimental methods taking unobserved heterogeneity into account can be divided. First, there are methods which control for the correlation between individual factors and program participation by using an adequate instrument. The second approach is to measure all individual factors that may be the cause of the correlation between individual factors and program participation and then, for example, match on these observed variables (Blundell, Dearden and Sianesi, 2005). For a review of different approaches see Heckman, LaLonde and Smith (1999) or Caliendo and Hujer (2005). Imbens (2004) describes methods for selection on observables, Angrist (2004) focuses on models where selection is influenced by unobservable heterogeneity. While selection models try to model the complete selection process, the IV method, which is used here, focuses on searching a source of independent variation affecting the decision to participate but not the outcome (in our case, earnings). Other estimation strategies are based on difference in difference estimation which erase only time-invariant selection.

In the following, a formal description of the basic framework of evaluation econometrics is given. Let $D$ indicate the choice of treatment, that is

$$
D= \begin{cases}1 & \text { if the individual receives treatment } \\ 0 & \text { otherwise }\end{cases}
$$

Concerning the outcome variable, it is assumed that latent values exist for every possible value of the treatment variable. These latent outcome variables are denoted by $Y_{1}$ and $Y_{0}$ for $D=1$ and $D=0$, respectively. Only one of the two latent outcomes can be observed, as every individual can solely choose one treatment status. Therefore, the observed outcome is given by $Y=D Y_{1}+(1-D) Y_{0}$. In the binary treatment case at hand, it means that every individual would receive an income in the treated as well as in the untreated case. $Y_{1}$ is observed for participants and $Y_{0}$ for nonparticipants. 
The causal effect of treatment $D$ on the outcome variable $Y$ is defined to be

$$
\Delta=Y_{1}-Y_{0} .
$$

This difference is unobservable for every individual, as either $Y_{1}$ or $Y_{0}$ cannot be observed. Different methods have been developed in the literature to overcome this problem. In general, averages of (1) for various subgroups are considered. The average treatment effect $\Delta^{\mathrm{ATE}}$ is the effect on an average individual of the population, whereas the average treatment effect on the treated $\Delta^{\mathrm{TT}}$ and the average treatment effect on the untreated $\Delta^{\mathrm{TUT}}$ state the effects for the subpopulations of treated and untreated individuals, respectively. Formally, the effects are defined by

$$
\begin{array}{rll}
\Delta^{\mathrm{ATE}}:= & E\left[Y_{1}-Y_{0}\right] \\
\Delta^{\mathrm{TT}}:= & E\left[Y_{1}-Y_{0} \mid D=1\right] \\
\Delta^{\mathrm{TUT}}:= & E\left[Y_{1}-Y_{0} \mid D=0\right]
\end{array}
$$

All effects can be defined conditional on $X$, for example $\Delta^{\mathrm{ATE}}(x)=E[\Delta \mid X=$ $x]$.

In the empirical analysis of this paper, we use the Local Instrumental Variable (LIV) method of Heckman and Vytlacil (1999, 2000, 2001, 2005) . First, the framework and underlying assumptions are described. Then we line out another causal effect, the marginal treatment effect, which was defined by Heckman and Vytlacil (1999) and relationships with the various types of causal effects are shown. Finally, the estimation strategy is outlined.

The treatment indicator $D$ is modelled by a latent index model:

$$
D=1\left(\mu_{D}(Z)-U_{D} \geq 0\right) .
$$

$1(A)$ is the indicator function, that is $1(A)=1$ if $A$ is true and $1(A)=0$ otherwise. $\mu_{D}(Z)$ is a function of some instrumental variables $Z$. The latent outcomes are functions of some observable variables $X$ and unobservable factors $U_{0}$ and $U_{1}$, i.e. $Y_{i}=g\left(X, U_{i}\right)$, for $i=1,2$. Participation in training corresponds to $D=1$, nonparticipants are identified by $D=0$.

Heckman and Vytlacil (1999, 2000, 2001, 2005) state the following assumptions:

- Given $X, \mu_{D}(Z)$ depends in a nontrivial way on $Z$. This corresponds to the usual assumption of instrument relevance in linear IV models, i.e., the instruments have to influence the training decicion after controlling for other covariates $X$.

- $U_{D}$ is independent from $X$ and all error terms in the model are independent from $Z$ given $X$. This is the usual exclusion restriction of IV models which states that $Z$ has no influence on the dependent variable 
after the covariates $X$ are accounted for. A detailed discussion of these assumptions in the context of evaluation models is given by Vytlacil (2002).

- The error term $U_{D}$ of the latent index model (5) is assumed to be absolutely continuous with respect to Lebesgue measure.

- Furthermore, $E\left|Y_{1}\right|$ and $E\left|Y_{0}\right|$ are assumed to be finite, which guarantees the existence of $E[Y]$.

- For every individual, the probablility of participation $P(D=1)$ lies strictly beetween zero and one, given the observable characteristics $X$.

With this setup, Heckman and Vytlacil (1999, 2000, 2001, 2005) define the marginal treatment effect, which is the causal effect of $D$ given $X$ and $U_{D}$ :

$$
\Delta^{\mathrm{MTE}}(x, u)=E\left[Y_{1}-Y_{0} \mid X=x, U_{D}=u\right]
$$

The marginal treatment effect provides a framework to obtain expressions for various average treatment effects. Heckman and Vytlacil (1999, 2000, 2001) derive the following relationships:

$$
\begin{aligned}
\Delta^{\mathrm{ATE}}(x) & =\int_{0}^{1} \Delta^{\mathrm{MTE}}(x, u) d u \\
\Delta^{\mathrm{TT}}(x) & =\int_{0}^{1} \Delta^{\mathrm{MTE}}(x, u) \frac{1-F_{P(Z) \mid X}(u \mid x)}{E[P(Z) \mid X]} d u \\
\Delta^{\mathrm{TUT}}(x) & =\int_{0}^{1} \Delta^{\mathrm{MTE}}(x, u) \frac{F_{P(Z) \mid X}(u \mid x)}{E[1-P(Z) \mid X]} d u .
\end{aligned}
$$

Here, $P(Z)$ is shorthand for $P(D=1 \mid Z)$. Therefore, integration of the suitable weighted marginal treatment effects over the $[0,1]$-interval yields estimates of treatment effects for different subpopulations. The basic ingredient of this procedure is the marginal treatment effect. To get an estimate of it, the Local Instrumental Variables (LIV) estimator was proposed by Heckman and Vytlacil (1999, 2000, 2001, 2005):

$$
\widehat{\Delta}^{\mathrm{MTE}}(x, P(z))=\frac{\partial E[Y \mid X=x, P(Z)=P(z)]}{\partial P(z)}
$$

The LIV method estimates the marginal treatment effect for $u=P(z)$. This can be seen by forming the derivative of the expectation of $Y$ given $P(Z)$ and noting that $Y=D Y_{1}+(1-D) Y_{0}$.

The definition of the local average treatment effect $\Delta^{\text {LATE }}$ of Imbens and Angrist (1994) can be used to motivate the marginal treatment effect. The LATE is defined by

$$
\begin{aligned}
& \Delta^{\operatorname{LATE}}\left(x, P(z), P\left(z^{\prime}\right)\right)= \\
& \frac{E[Y \mid P(Z)=P(z), X=x]-E\left[Y \mid P(Z)=P\left(z^{\prime}\right), X=x\right]}{P(D=1 \mid Z=z)-P\left(D=1 \mid Z=z^{\prime}\right)} .
\end{aligned}
$$


This is the treatment effect for the subgroup of individuals who change their treatment status due to a change of the instrument $Z$ from $z$ to $z^{\prime}$. This subgroup of so-called compliers cannot be identified in a given dataset. For comments and criticism of this concept see Heckman (1997) and Angrist, Imbens and Rubin (1996) and the accompanying discussions. Considering $P(z) \rightarrow P\left(z^{\prime}\right)$, the expression of the LATE tends to the derivative of the conditional expectation of $Y$ :

$$
\lim _{P(z) \rightarrow P\left(z^{\prime}\right)} \Delta^{\operatorname{LATE}}\left(x, P(z), P\left(z^{\prime}\right)\right)=\frac{\partial E[Y \mid X=x, P(Z)=P(z)]}{\partial P(z)} .
$$

The LIV-estimator estimates some sort of marginal LATE. Therefore, the marginal treatment effect can be interpreted as the effect on an individual with observable characteristics $X$ and unobservables $U_{D}$ which is indifferent about participation.

\section{Data}

For our analysis, we use a rich and representative German data set with information on 0.1 percent of all individuals employed in 1998/1999 - the BIBB/IAB data set "Qualification and Career Survey". The cross-section data allow an assessment of the impact of training measures in 1996-98 on wages in 1998/1999. Our sample contains more than 7,400 male (fulltime) employees from West Germany. We include about 70 explanatory variables that capture the salient employer and employee characteristics for wage determination (see also table 2 in the appendix for the complete list with detailed descriptions).

The outcome variable is log midpoints of earnings in 1998/1999 from 18 earnings categories in the data. This variable has the advantage that earnings of highly paid workers are not censored from above.

The key explanatory variable is participation in training courses and seminars that serve professional development during the years 1996 to 1998. This dummy might stand for quite substantial amounts of training, because employees might participate in various courses during 24 months. In addition, only formal training courses are included in the data set and short or informal training spells are explicitly excluded. Note that apprenticeship training is also excluded. Unfortunately, we don't have information about the content and the length of courses and we do not know the costs of training or who bears them. 58 percent of the employees participated in further training according to this definition (table 2 in the appendix). Participation differs tremendously for low and high skilled employees: while only around 30 percent of the workers without professional degree participated in training, 50 percent of the employees with a vocational school degree or an apprenticeship training took part in some kind of training during the last two 
years, and about 80 percent of high skilled employees ( master craftsman, university of applied sciences, and university degree) participated. Training participation also varies with age: 30 - 45 year old employees receive most training, older worker participate less (see figures 1 and 2 in the appendix). In our estimations, we use three different instrumental variables. The first instrument we use is the training intensity by industry, estimated from an earlier wave (1991/1992) of the BIBB/IAB-survey. Theoretically, it is not plausible that training intensity per sector in 1991/1992 influences individual wages in 1998/1999. In contrasts, it is very likely that individuals which are employed in a sector with a high training intensity in 1991/1992 have a higher chance to participate in training in 1998/1999 than individuals in an economic sector with a low training intensity in 1991/1992. Empirically, the training intensity per economic sector in 1991/1992 is not correlated with earnings seven years later but influences the individual probability to take part in training. Also, we imputed data from the Continuing Vocational Training Survey (CVTS 2000) about sectoral shares of firms and shares of firms by employment size that include continuous training in their collective bargaining agreement 1 There is no obvious link of this variable with individual earnings, using additionally sector dummies as covariates, but it influences the individual probability to take part in training. As third instrumental variable, we use a dummy variable indicating whether workers are employed in a modern job (in contrast to a traditional job) because the demand for training is higher in these jobs. After controlling for economic sector and occupation, we consider it as an valid instrument (compare results of the propensity score, table 3 ).

Further determinants of earnings are those found in the Mincer equation, i.e. actual work experience ${ }^{2}$ job tenure, former unemployment, and dummies for the highest educational achievement ${ }^{3}$ These variables are related to the situation in 1998/1999. Together with these standard variables, we also include 11 dummies capturing the professional status, such as blue-collar or white-collar worker, civil servant or different sophistication levels of tasks for 1998/1999.

In addition, we use the following current job characteristics: computer use, profit-sharing, bonus payments, overtime work, whether a job is temporary, and 13 dummies for main job contents. These variables allow us to control a part of the individual heterogeneity between the employees. 4 Some of these

\footnotetext{
${ }^{1}$ The CVTS data is from 1999 and therefore fits well to the BIBB/IAB data set.

${ }^{2}$ We know when the individual started his or her first job and we include dummies for discontinuation such as unemployment.

${ }^{3}$ In Germany, the highest schooling degree is more informative for the level of education than years of schooling (Georegellis and Lange, 1997).

${ }^{4}$ Some of these variables may also be endogenous in the earnings equation. We do not control for this, because those variables mainly serve as control variables for employee heterogeneity.
} 
variables (for example working overtime) can be interpreted as indicators of intrinsic motivation. Additional control variables explaining earnings are personal attributes. We include a dummy for children and non-German nationality.

Finally, we add some employer characteristics: seven dummies for firm size, 5 dummies indicating the economic sector of the employer, 11 dummies for the federal state the firm is located in, and a dummy indicating whether the firm is in a good economic situation in 1998/1999.

Only full-tim ${ }^{5}$ employees (without self-employed) in West Germany are included, because in 1998 there were still large differences in the labor market structures of the two parts of the country. The analysis is restricted to male employees, because the data do not allow us to model participation in the labor market simultaneously, which would be important for examining earnings effects for women $\sqrt{6}$ This reduces the sample to around 7,500 individuals. The descriptive characteristics of the variables used can be found in table 2 in the appendix.

In order to obtain clean evidence on the earnings effects of employer-provided training, we exclude those training participants where we cannot be sure whether they were employed or unemployed while being trained (about 450 cases). The reason for this restriction is that we want to exclude training provided by government aimed at unemployed. Wage effects of training should differ for those employees which stay with a firm and those which move (Booth and Bryan, 2005; Gerfin, 2004; Loewenstein and Spletzer, 1998; Lynch, 1992; OECD, 2004; Garloff and Kuckulenz, 2006). In our data set we can only identify very few individuals which change their employer after attending continuing training. We cannot show any significant difference between job stayers and movers and hence, we restrict our sample to those which stay with their employer.

\section{$5 \quad$ Implementation and Results}

The basic building blocks of the empirical analysis are estimates of $\Delta^{\mathrm{MTE}}(x, u)$. For this purpose, estimates of the derivative of the conditional expectation of $Y$ given $X$ and $P(Z)$ are needed. The latent outcome equations are specified

\footnotetext{
${ }^{5}$ We include only employees working 30 hours and above per week. Only 2.6 percent of the male employees work less than 30 hours. We also use a dummy for working overtime in order to take hours worked into account. The results do not change qualitatively, however, if we use log hourly wages instead of log earnings as the dependent variable.

${ }^{6}$ In order to include women, we would need to correct for sample selection in the earnings equation. This is impossible since only those women who participate in the labor market are included in the data.
} 
as:

$$
\begin{aligned}
& \ln Y_{1}=\alpha_{1}+X \theta_{1}+U_{1} \\
& \ln Y_{0}=\alpha_{0}+X \theta_{0}+U_{0}
\end{aligned}
$$

The observable outcome is therefore given by

$$
\begin{aligned}
\ln Y= & D \ln Y_{1}+(1-D) \ln Y_{0} \\
= & \alpha_{0}+X \theta_{0}+D\left(\alpha_{1}-\alpha_{0}\right)+D X\left(\theta_{1}-\theta_{0}\right) \\
& +D U_{1}+(1-D) U_{0} .
\end{aligned}
$$

From this, the conditional expectation of $\ln Y$ given $X$ and $P(Z)$ follows as

$$
\begin{aligned}
E[\ln Y \mid X, P(Z)]= & \alpha_{0}+X \theta_{0}+P(Z)\left(\alpha_{1}-\alpha_{0}\right)+P(Z) X\left(\theta_{1}-\theta_{0}\right)+ \\
& P(Z) E\left[U_{1} \mid P(Z)\right]+(1-P(Z)) E\left[U_{0} \mid P(Z)\right]
\end{aligned}
$$

The derivative of 16 with respect to $P(Z)$ is given by

$$
\frac{\partial E[\ln Y \mid X, P(Z)]}{\partial P(Z)}=\left(\alpha_{1}-\alpha_{0}\right)+X\left(\theta_{1}-\theta_{0}\right)+K(P(Z))
$$

where $K(P(Z))=\frac{\partial\left(P(Z) E\left[U_{1} \mid P(Z)\right]+(1-P(Z)) E\left[U_{0} \mid P(Z)\right]\right)}{\partial P(Z)}$. To estimate $\Delta^{\mathrm{MTE}}(x, u)$, pointwise estimates for all $X$ and $U$ (within the $[0,1]$ interval) are needed. To reduce the dimension of the problem, the expectation is modelled as a partial linear model (see Carneiro, Heckman and Vytlacil, 2003). The constant term and the term depending on $X$ enter the conditional expectation linearly, whereas $K(P(Z))$ is modelled nonparametrically. To estimate these characteristics of the equation, the "double residual regression" of Heckman, Ichimura, Smith and Todd (1998) is used. This slight variation of the partial linear model of Robinson (1988) is tailored for the evaluation of binary treatment effects. First, equation (15) is rewritten in the following form:

$$
\begin{aligned}
\ln Y= & \alpha_{0}+X \theta_{0}+D\left(\alpha_{1}-\alpha_{0}\right)+D X\left(\theta_{1}-\theta_{0}\right)+D U_{1}+(1-D) U_{0} \\
& +P(Z) E\left[U_{1} \mid P(Z)\right]+(1-P(Z)) E\left[U_{0} \mid P(Z)\right] \\
& -P(Z) E\left[U_{1} \mid P(Z)\right]-(1-P(Z)) E\left[U_{0} \mid P(Z)\right]
\end{aligned}
$$

The term $D U_{1}+(1-D) U_{0}-P(Z) E\left[U_{1} \mid P(Z)\right]-(1-P(Z)) E\left[U_{0} \mid P(Z)\right]$ is gathered in an error term $\varepsilon$, which has mean zero given $P(Z)$ by construction:

$$
\begin{aligned}
\ln Y= & \alpha_{0}+X \theta_{0}+D\left(\alpha_{1}-\alpha_{0}\right)+D X\left(\theta_{1}-\theta_{0}\right) \\
& +P(Z) E\left[U_{1} \mid P(Z)\right]+(1-P(Z)) E\left[U_{0} \mid P(Z)\right]+\varepsilon
\end{aligned}
$$

In parlance of partial linear models, the term $P(Z) E\left[U_{1} \mid P(Z)\right]+(1-P(Z))$ $E\left[U_{0} \mid P(Z)\right]$ is the nonparametric component. From this, the conditional 
expectation of $\ln Y$ given $P(Z)$ follows:

$$
\begin{aligned}
E(\ln Y \mid P(Z))= & \alpha_{0}+E(X \mid P(Z)) \theta_{0}+P(Z)\left(\alpha_{1}-\alpha_{0}\right) \\
& +P(Z) E(X \mid P(Z))\left(\theta_{1}-\theta_{0}\right)+P(Z) E\left[U_{1} \mid P(Z)\right] \\
& +(1-P(Z)) E\left[U_{0} \mid P(Z)\right]
\end{aligned}
$$

Subtracting (20) from (19) yields:

$$
\begin{gathered}
\ln Y-E[\ln Y \mid P(Z)]=(X-E[X \mid P(Z)]) \theta_{0}+(D-P(Z)) \times \\
\left(\alpha_{1}-\alpha_{0}\right)+(D X-P(Z) E[X \mid P(Z)])\left(\theta_{1}-\theta_{0}\right)+\varepsilon
\end{gathered}
$$

The conditional expectations $E[X \mid P(Z)]$ are estimated pointwise by locallinear regressions. After forming the differences, $(21)$ is estimated by OLS. Using the estimated residuals from this regression, the derivatives of $P(Z)$ $E\left[U_{1} \mid P(Z)\right]+(1-P(Z)) E\left[U_{0} \mid P(Z)\right]$ can be estimated by the appropriate coefficients of local polynomial regressions. Using the empirical distributions of $F(P(Z) \mid X)$, the weights for the integration of $\Delta^{\mathrm{MTE}}(x, u)$ over $[0,1]$ can be computed. Using the empirical distribution of $X$, unconditional treatment effects can be obtained. To judge the significance of the estimated effects, confidence intervals based on 50 bootstrap samples are computed.

The propensity score is specified as a probit model. The estimated coefficients are contained in table 3 in the appendix. All instruments are significant.

The estimated treatment effects and the bootstrap confidence intervals are contained in table 1. The point estimates of the treatment effects are negative. However, the confidence intervals show that the effects are not statistically significant. Therefore, no statements about the sign of the effect can be made. The wide confidence intervals show a considerable uncertainty about the causal effect of training.

The LIV estimates are lower than the relevant OLS estimate, which is 0.03 (t-value: 3.62 ) and considerably lower than the standard IV estimator, using the same instruments, which is 0.21 ( $\mathrm{t}$-value: 2.37 ). The latter results suggest a significant positive effect of training on wages. The insignificant LIV-estimates cannot support this conclusion. That is, using a method with considerably weaker assumptions on individual behavior than OLS or linear IV, the qualitative results of the latter cannot be confirmed. Therefore, the positive relationship claimed by conventional estimates has to be questioned. This is in line with the supposition stated in the literature, that estimates which do not account for (unobserved) heterogeneity and the selection in this regard are upward biased. We interpret our result that training does not have an impact on earnings itself but only in combination with unobserved factors. It is likely that training is part of a promotion path and that not a certain training, but a career track as a whole leads to earnings growth. 
Table 1: Estimates of the treatment effects

\begin{tabular}{|c|c|c|c|}
\hline & Original & \multicolumn{2}{|c|}{ Bootstrap samples } \\
& sample & \multicolumn{2}{|c|}{ Confidence intervals } \\
& & $90 \%$ & $95 \%$ \\
\hline TUT & -.077 & $(-.123, .015)$ & $(-.145, .039)$ \\
ATE & -.073 & $(-.119, .015)$ & $(-.142, .038)$ \\
TT & -.063 & $(-.112, .014)$ & $(-.134, .032)$ \\
\hline
\end{tabular}

Firms provide training to individuals only when the expected return of this investment is positive. Hence, training participants might be more able and motivated and therefore also be on such a track with higher earnings growth. When this unobserved heterogeneity is taken into account in the selection into training, the positive training impact estimated by conventional OLS or IV estimates vanishes.

\section{Conclusion}

With German survey data from 1998/1999, we examine the heterogeneity of training returns and whether these may have an effect on training participation. Using the local IV method, which allows for the likely fact that the expected return of the investment in human capital plays a role when deciding about the investment, we are able to account for heterogeneity of training returns in earnings equations. The LIV estimator allows for observed as well as unobserved heterogeneity and selection into training may depend on both. Former work on the wage impact of training has suggested that selection on unobservables might be important and hence, traditional estimators used might incorporate an upward bias.

Our LIV estimate is much lower than the relevant OLS and IV estimate (and furthermore, insignificant). We cannot find any causal effect of training on wages when taking into account that more able and motivated individuals participate in training, or those which are on a promotion path where training courses are part of the way. For future work it would be useful to use comprehensive information on career tracks and promotion in order to distinguish the impact of certain personnel measures.

\section{References}

AmmermülleR, A. (2004): "PISA: What Makes the Difference? Explaining the Gap in PISA Test Scores Between Finland and Germany," $Z E W$ Discussion Paper, (04-04). 
AngRist, J. (2004): "Treatment Effect Heterogeneity in Theory and Practice," Economic Journal, 114, C52-C83.

Angrist, J., G. Imbens, And D. Rubin (1996): "Identification of Causal Effects Using Instrumental Variables," Journal of the American Statistical Association, 91, 444-472.

Arulampalam, W., A. L. Booth, and M. L. Bryan (2004): "Are There Asymmetries in the Effects of Training on the Conditional Male Wage Distribution?," Discussion Paper 984, IZA, Bonn.

Barron, J. M., M. C. Berger, and D. A.Black (1999): "Do Workers Pay for On-the-Job Training?," Journal of Human Resources, 34(2), 236252.

Blundell, R., L. Dearden, and C. Meghir (1996): The Determinants and Effects of Work-Related Training in Britain. Institute for Fiscal Studies, London.

(1999): "Work-Related Training and Earnings," Discussion paper, Institute for Fiscal Studies, London.

Blundell, R., L. Dearden, and B. Sianesi (2005): "Evaluating the effect of education on earnings: Models, methods and results from the National Child Development Survey," Journal of the Royal Statistical Society: Series A, 168, 473-512.

Booth, A. L., and M. L. Bryan (2005): "Testing Some Predictions of Human Capital Theory: New Training Evidence from Britain," The Review of Economics and Statistics, 87(2), 391-394.

Caliendo, M., and R. Hujer (2005): "The Microeconometric Estimation of Treatment Effects - An Overview," IZA Discussion Paper, 1653.

Carneiro, P., J. Heckman, and E. Vyctlacil (2003): "Estimating the Return to Education When It Varies Among Individuals," mimeo, University of Chicago.

Dearden, L., H. Reed, and J. V. Reenen (2000): "Who Gains When Workers Train? Training and Corporate Productivity in a Panel of British Industries," .

Garloff, A., And A. Kuckulenz (2006): "Training, mobility and wages: specific versus general human capital," Jahrbücher für Nationalökonomie und Statistik, forthcoming.

Georgellis, Y., And T. LAnge (1997): "The Effect of Further Training on Wage Growth in West Germany, 1984-1992," Scottish Journal of Political Economy, 44(2), 165-181. 
Gerfin, M. (2004): "Work-Related Training and Wages: An Empirical Analysis for Male Workers in Switzerland," Discussion Paper 1078, IZA, Bonn.

Heckman, J. J. (1997): "Instrumental variables: a study of implicit behavioral assumptions used in making program evaluations," Journal of Human Resources, 32, 441-462.

Heckman, J. J., H. Ichimura, J. Smith, and P. Todd (1998): "Characterizing selection bias using experimental data," Econometrica, 66, 10171098.

Heckman, J. J., R. J. LaLonde, and J. A. Smith (1999): "The economics and econometrics of active labor markets programs," in Handbook of Labor Economics, ed. by A. Ashenfelter, and D. Card, vol. 3, pp. 18642097. North Holland, Amsterdam.

Heckman, J. J., and E. J. Vytlacil (1999): "Local instrumental variables and latent variable models for identifying and bounding treatment effects," Proceedings of the National Academy of Sciences, 96, 4730-4734.

(2000): "The relationship between treatment parameters within a latent variable framework," Economic Letters, 66, 33-39.

- (2001): "Local instrumental variables," in Nonlinear statistical modelling, ed. by C. Hsiao, K. Morimune, and J. J. Powell, pp. 1-46. Cambridge University Press, Cambridge.

Heckman, J. J., and E. J. Vytlacil (2005): "Structural Equations, Treatment Effects and Econometric Policy Evaluation," Econometrica, $73,669-738$.

ImBens, G. (2004): "Nonparametric Estimation of Average Treatment Effects under Exogeneity: A Review," Review of Economics and Statistics, $86,4-29$.

Imbens, G. W., And J. D. Angrist (1994): "Identification and Estimation of Local Average Treatment Effects," Econometrica, 62, 467-475.

Jürges, H., AND K. Schneider (2005): "Dynamische Lohneffekte berufliche Weiterbildung - Eine Längsschnittanalyse mit den Daten des SOEP," Discussion Paper No. 92, MEA, Mannheim.

Kuckulenz, A., And T. Zwick (2003): "The Impact of Training on Earnings - Differences Between Participant Groups and Training Forms," ZEW Discussion Paper No. 03-57, Mannheim.

Lauer, C. (2002): "A Model of Educational Attainment Application to the German Case," ZEW Discussion Paper, (02-06). 
LAZEAR, E. P. (1979): "Why Is There Mandatory Retirement?," The Journal of Political Economy, 87(6), 1261-1284.

Leuven, E. (2005): "The Economics of Training: A Survey of the Literature," Journal of Economic Surveys, 19(1), 91-111.

Leuven, E., And H. Oosterbeek (2001): "Firm-Specific Human Capital as a Shared Investment: Comment," American Economic Review, 91, $342-347$.

(2002): "A New Approach to Estimate the Wage Returns to WorkRelated Training," IZA Discussion Paper, No. 526.

Loewenstein, M. A., And J. R. Spletzer (1998): "Dividing the Costs and Returns to General Training," Journal of Labor Economics, 16(1), $142-171$.

Lynch, L. M. (1992): "Private-Sector Training and the Earnings of Young Workers," The American Economic Review, 82(1), 299-312.

OECD (1999): Employment Outlook. OECD, Paris.

_ (2004): Employment Outlook. OECD, Paris.

Pannenberg, M. (1998): "Weiterbildung, Betriebszugehörigkeit und Löhne: Ökonomische Effekte des "Timings" von Investitionen in die berufliche Weiterbildung," in Qualifikation, Weiterbildung und Arbeitsmarkterfolg, ed. by F. Pfeiffer, and W. Pohlmeier, vol. 31 of $Z E W$ Wirtschaftsanalysen, pp. 257-279. Nomos, Baden-Baden.

Pfeiffer, F., and F. Reize (2001): "Formelle und informelle berufliche Weiterbildung und Verdienst bei Arbeitnehmern und Selbstständigen," in Bildung und Beschäftigung, ed. by R. K. Weizsäcker, no. 284 in Schriften des Vereins für Socialpolitik, pp. 215-274. Duncker und Humblot, Berlin.

Pischke, J.-S. (2001): "Continuous Training in Germany," Journal of Population Economics, 14, 523-548.

Robinson, P. M. (1988): "Root-n-consistent semiparametric regression," Econometrica, 56, 931-954.

Vytlacil, E. (2002): "Independence, Monotonicity, and Latent Index Models: An Equivalence Result," Econometrica, 70, 331-341.

Weiss, R. (2000): "Wettbewerbsfaktor Weiterbildung, Ergebnisse der Weiterbildungserhebung der Wirtschaft," Discussion Paper 242, Beiträge zu Bildungs- und Gesellschaftspolitik des Instituts der deutschen Wirtschaft, Köln. 
(2003): "Betriebliche Weiterbildung 2001 - Ergebnisse einer IWErhebung," iw-trends. 


\section{A Appendix}

\section{A.1 Tables}

Table 2: List of Variables Used

\begin{tabular}{|c|c|c|}
\hline Variable & Share/Average & Notes \\
\hline \multicolumn{3}{|c|}{ Earnings } \\
\hline Less than 600 DM & $0.09 \%$ & \\
\hline Between 600 and $1000 \mathrm{DM}$ & $0.12 \%$ & \\
\hline Between 1000 and 1500 DM & $0.32 \%$ & \\
\hline Between 1500 and 2000 DM & $1.20 \%$ & \\
\hline Between 2000 and $2500 \mathrm{DM}$ & $4.24 \%$ & \\
\hline Between 2500 and $3000 \mathrm{DM}$ & $7.54 \%$ & \\
\hline Between 3000 and $3500 \mathrm{DM}$ & $11.98 \%$ & \\
\hline Between 3500 and 4000 DM & $14.75 \%$ & \\
\hline Between 4000 and $4500 \mathrm{DM}$ & $14.13 \%$ & \\
\hline Between 4500 and $5000 \mathrm{DM}$ & $12.19 \%$ & \\
\hline Between 5000 and $5500 \mathrm{DM}$ & $8.14 \%$ & \\
\hline Between 5500 and $6000 \mathrm{DM}$ & $7.15 \%$ & \\
\hline Between 6000 and $7000 \mathrm{DM}$ & $7.15 \%$ & \\
\hline Between 7000 and $8000 \mathrm{DM}$ & $4.04 \%$ & \\
\hline Between 8000 and $9000 \mathrm{DM}$ & $2.70 \%$ & \\
\hline Between 9000 and 10000 DM & $1.51 \%$ & \\
\hline Between 10000 and 15000 DM & $2.22 \%$ & \\
\hline $15000 \mathrm{DM}$ and more & $0.53 \%$ & \\
\hline \multicolumn{3}{|c|}{ School Attainment } \\
\hline Without School Leaving Certificate & $2.28 \%$ & \\
\hline Lower Secondary School & $51.33 \%$ & \\
\hline Intermediate Secondary School & $25.20 \%$ & \\
\hline Entrance Examination for & $7.93 \%$ & \\
\hline University of Applied Sciences & & \\
\hline High School Diploma & $13.25 \%$ & \\
\hline \multicolumn{3}{|c|}{ Vocational Training } \\
\hline Without Professional Degree & $12.08 \%$ & \\
\hline Full-Time Vocational School & $2.37 \%$ & $\begin{array}{l}\text { Several years of professional } \\
\text { training in school }\end{array}$ \\
\hline Dual Apprenticeship & $61.30 \%$ & Several years of professional \\
\hline Master Craftsman & $12.64 \%$ & \\
\hline University of Applied Sciences & $4.92 \%$ & \\
\hline University & $6.35 \%$ & \\
\hline \multicolumn{3}{|c|}{ Training } \\
\hline Training & $58.08 \%$ & \\
\hline
\end{tabular}


Table 2: List of Variables Used (continued)

\begin{tabular}{|c|c|c|}
\hline Variable & Share/Average & Notes \\
\hline \multicolumn{3}{|c|}{ Professional Career } \\
\hline Professional Experience & 21.87 years & Years from first job until today \\
\hline Company Tenure & 12.91 years & $\begin{array}{l}\text { Years from starting to work for } \\
\text { a company until today }\end{array}$ \\
\hline Unemployment & $29.85 \%$ & $\begin{array}{l}\text { Dummy }=1 \text { if a person was } \\
\text { ever employed, otherwise } 0\end{array}$ \\
\hline \multicolumn{3}{|c|}{ Workplace Characteristics } \\
\hline Computer Work Station & $49.37 \%$ & $\begin{array}{l}\text { Work routine includes using } \\
\text { the computer }\end{array}$ \\
\hline Temporary Work & $49.36 \%$ & \\
\hline Good Economic Situation & $63.25 \%$ & \\
\hline Working Hours & 177.21 hours & Working hours per month \\
\hline Overtime & $79.95 \%$ & $\begin{array}{l}\text { Dummy }=1 \text { if a person works } \\
\text { overtime, otherwise } 0\end{array}$ \\
\hline Paid Overtime & $35.93 \%$ & \\
\hline Overqualified & $36.50 \%$ & \\
\hline Profit-Sharing & $9.20 \%$ & \\
\hline Incentive Wage & $24.11 \%$ & \\
\hline Good Economic Situation & $63.25 \%$ & $\begin{array}{l}\text { Dummy }=1 \text { if the company is in } \\
\text { a good economic situation, } \\
\text { otherwise } 0\end{array}$ \\
\hline Modern Job & $12.06 \%$ & \\
\hline \multicolumn{3}{|c|}{ Individual Characteristics } \\
\hline Children & $48.51 \%$ & $\begin{array}{l}\text { Dummy }=1 \text { if a person has at } \\
\text { least one child, otherwise } 0\end{array}$ \\
\hline Foreigner & $5.43 \%$ & $\begin{array}{l}\text { Dummy }=1 \text { if a person does } \\
\text { not have a German Nationality, } \\
\text { otherwise } 0\end{array}$ \\
\hline Not Married & $7.33 \%$ & \\
\hline Handicapped & $4.85 \%$ & \\
\hline \multicolumn{3}{|c|}{ Other Variables } \\
\hline $\begin{array}{l}\text { Size of Firm } \\
\text { Professional Status } \\
\text { Federal State } \\
\text { Economic Sector }\end{array}$ & & $\begin{array}{l}7 \text { Categories } \\
12 \text { Categories } \\
11 \text { Categories: all Federal } \\
\text { States of West Germany } \\
5 \text { Categories }\end{array}$ \\
\hline
\end{tabular}


Table 3: Estimation results for the propensity score

\begin{tabular}{|l|c|c|}
\hline \multicolumn{1}{|c|}{ Parameters } & Estimates & Z - Values \\
\hline Training Intensity 91 & 1.26 & 5.29 \\
Bargaining Agreement & 1.84 & 3.03 \\
Modern Job & 0.18 & 3.42 \\
Lower Secondary School & 0.29 & 1.91 \\
Intermediate Secondary School & 0.29 & 1.92 \\
Entrance Examination for & 0.30 & 1.91 \\
University of Applied Sciences & & \\
High School Diploma & 0.23 & 1.43 \\
Full-Time Vocational School & 0.01 & 0.07 \\
Dual Apprenticeship & 0.19 & 2.58 \\
Master Craftsman & 0.23 & 2.61 \\
University of Applied Sciences & 0.21 & 2.00 \\
University & 0.10 & 0.90 \\
Professional Experience & 0.05 & 0.72 \\
Company Tenure & 0.35 & 5.02 \\
Unemployment & -0.00 & -0.11 \\
Computer Work Station & 0.36 & 7.59 \\
Temporary Work & -0.24 & -2.52 \\
Paid Overtime & -0.03 & -0.76 \\
Working Hours & 0.34 & 4.34 \\
Overqualified & -0.03 & -0.69 \\
Profit-Sharing & 0.04 & 0.59 \\
Incentive Wage & 0.13 & 3.04 \\
Good Economic Situation & -0.02 & -0.43 \\
Children & 0.08 & 2.00 \\
Not Married & 0.01 & 0.12 \\
Handicapped & 0.01 & 0.10 \\
Constant & -3.37 & -11.52 \\
\hline Number of Observations & 7417 & \\
LR-Test ( $\left.\chi^{2}(72)\right)$ & 1987.10 & \\
P-value of LR-Test & 0.00 & \\
Dumy varo & \\
\hline
\end{tabular}

Dummy variables are included for size of firm, professional status, federal state, and economic sector.

Instruments included are: technical restructuring, organizational restructuring, three measures of personnel restructuring (hiring of additional workers, downsizing, and hiring of temporary workers), a dummy variable indicating whether workers are employed in a modern job, and sectoral shares of firms by employment size that include continuous training in their collective bargaining agreement. 


\section{A.2 Figures}

Figure 1: Training Participation per Age Groups

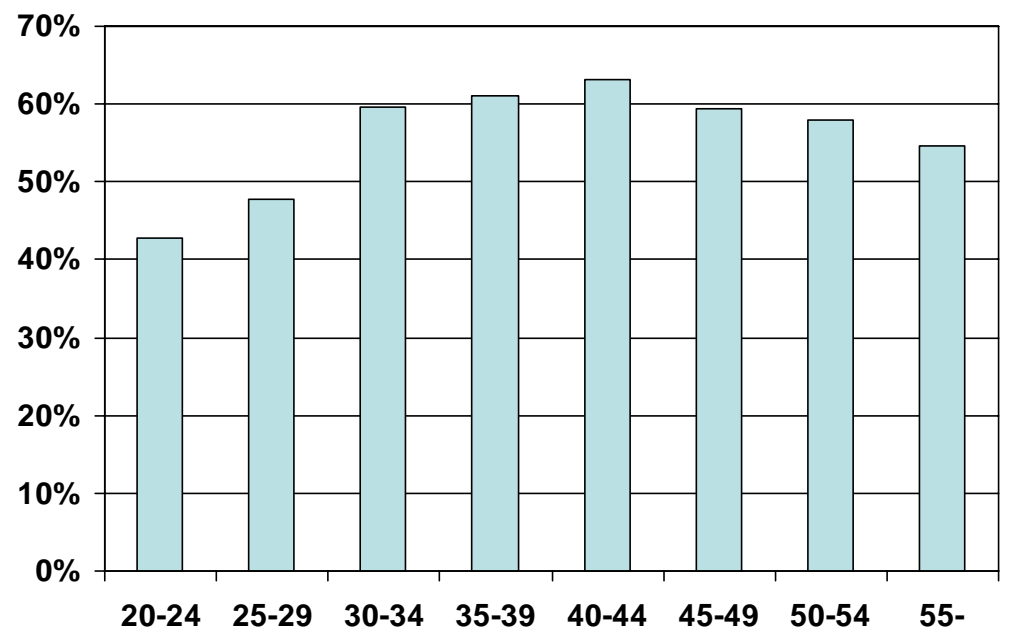

Figure 2: Training Participation per Qualification Groups

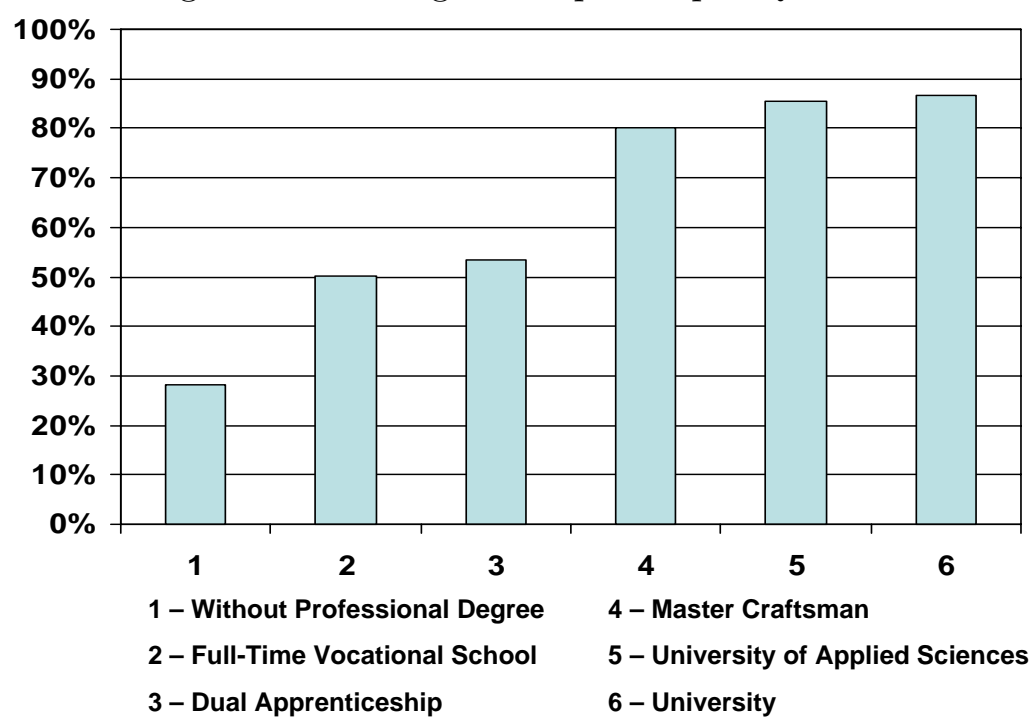

